\title{
Efficient Power Electronic Converters for Electrical Vehicle Application
}

\author{
Muddasani Sampathkumar ${ }^{a}$, Dr. A S Rathore ${ }^{b}$ and Dr. A. Prasad Raju \\ a Research Scholar, Dept. of Electrical \& Electronics Engineering, \\ Sri Satya Sai University of Technology \& Medical Sciences, Sehore, Bhopal Indore Road, Madhya Pradesh, India \\ ${ }^{\mathbf{b}}$ Research Guide, Dept. of Electrical \& Electronics Engineering, \\ Sri Satya Sai University of Technology \& Medical Sciences, Sehore, Bhopal Indore Road, Madhya Pradesh, India \\ ${ }^{c}$ Research Co-Guide, Sree Chaitanya Institute of Technological Sciences, Karim Nagar, Telangana.
}

Article History: Received: 11 January 2021; Accepted: 27 February 2021; Published online: 5 April 2021

\begin{abstract}
Now a days we are looking for alternate sources like electric vehicles, in order to cut down the pollution from automobiles which are growing rapidly. Across the globe, governments have been tackling the concerning problem of airpolluting emissions by committing significant resources to improving air quality. Achieving the goal of air purification will require that both the private and public sectors invest in clean energy technology. It will also need a transition from conventional houses to smart houses and from conventional vehicles to electric vehicles (EVs). It will be necessary to integrate renewable energy sources (RESs) such as solar photovoltaics, wind energy systems and diverse varieties of bioenergies. In this paper, a hybrid converter is proposed and designed to realize the integration of the DC/DC converter, and DC/AC inverter together in the Battery Electric Vehicles (BEVs) power train with high performance in any operating mode, acting as a backup generator to supply emergency power directly to home.
\end{abstract}

Keywords: Hybrid converter, Electrical Vehicle, Coupled Inductor, Battery Electric Vehicles (BEV)

\section{Introduction}

Renewable energy technologies such as fuel cell and solar are gaining popularity for vehicle application. Not only these energy sources reduce gas in the cities but they also reduce dependability on the fossil energy. As a platform to exchange ideas and research findings related to solar vehicles, North American Solar Challenge. One of the highlights of the event is the solar racecar. This initiative ignites interests of many researchers to develop high efficiency power generated solar, improve aerodynamic and reduce losses in mechanical and electrical in the car. As solar power depends on the sunlight, such vehicle needs secondary sources to drive at night or in cloudy conditions. Alternatively, fuel cell can work all day long as long as hydrogen is available in the tank. Unfortunately, fuel cell has slow response in high power condition and it also needs supercapacitors to overcome its low start-up time. As a result, supercapacitors are a mandatory part in every fuel cell powered system in hybrid electrical vehicle (HEV). In order to minimize the usage of energy and fulfill different stage of power condition, an innovative energy management system is required to coordinate these multi energy sources.

The electric vehicles are mainly classified in two different types as Plugin Electric vehicle (PEV) and Hybrid Electric vehicle (HEV). These electric vehicles improves the efficiency of vehicles and also severs to reduce the environmental pollution due to IC engines.

\section{Types of Electric Vehicles}

The electric vehicles are classified on the basis of their powertrain i.e. electric dive is the key part of both Plug in Electric vehicle\&Hybrid Electric vehicle

\section{Plug in Electric vehicle (PEV)}

Plug in electric vehicle has the simplest construction of all it has components such as battery, converter, motor, gear system as show in figure 1 Battery is used to store energy, which is converted to in to dc or ac according the drive used to drive the vehicle. The motor may be asynchronous motor i.e. induction motor, dc motor, brushless dc motor synchronous motor in which permanent magnet synchronous motor has very good efficiency. It is also possible to place more than one motor for splitting the torque. The motors are placed in wheel hubs. But in this case, each motor needs a separate converter with speed and torque control, which guarantees the necessary torque splitting in each condition. An electric vehicle is an emission free, environmental friendly vehicle. These PEVs have a disadvantage of battery getting discharged faster so it's not being used at a larger scale as they cannot travel a long distance.

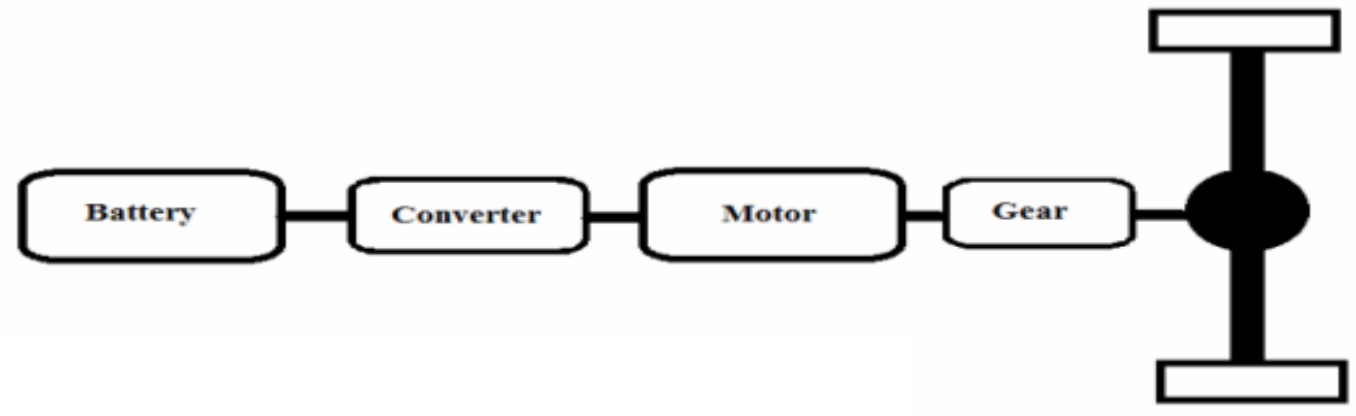

Figure 1 Plug in Electric Vehicle 


\section{Hybrid Electric vehicle(HEV)}

The electric vehicle with electric drive and an additional power source such as internal combustion engine, or any other electric motor supplying to the powertrain of vehicle with different energy source to drive the vehicle is called as hybrid electric vehicle where both electrical and other energy system are integrated together to drive the vehicle.

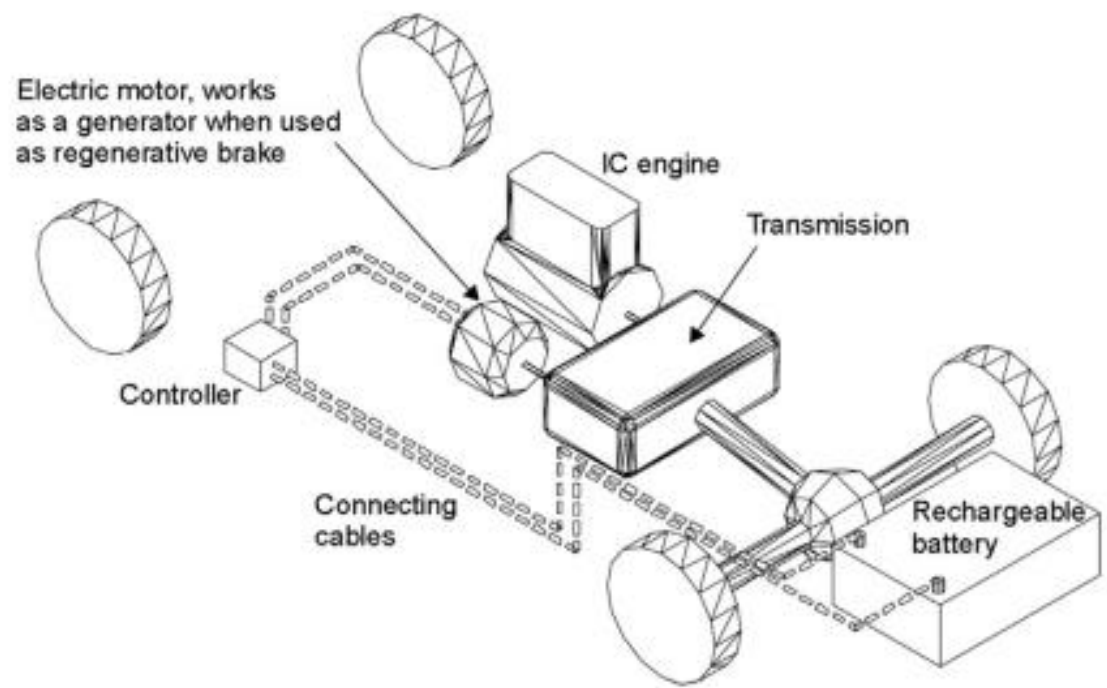

Figure 2 Architecture of parallel hybrid EVs

Hybrid electric vehicles powered by electric machines and an internet combustion engine are a promising means of reducing emissions and fuel consumption without compromising vehicle functionality and driving performances. Leading car manufacturers like Toyota and Honda have already started mass producing Hybrid electric cars, Prius and Insight respectively, which are now becoming very popular among the consumers for their incredible mileage and less emissions. Aside from that, a number of automotive manufacturers are marketing hybrid vehicles for the general population, examples are Daimler Chrysler, Mitsubishi, Nissan, Fiat, Renault, Ford, GM, and Subaru.

The HEVs further are classified on the basis of role of electric drive in the vehicle they are:

\section{Series HEV}

In series HEV configuration, only the electric motor is connected to the drive train and thus the vehicle is entirely driven by the electric motor. The Internal Combustion (IC) engine drives an electric generator (commonly known as alternator), which then supplies the electric power to the motor and battery pack.

\section{Parallel HEV:}

In the parallel HEV configuration there are two power paths for the drive train, while one comes from the engine the other comes from the electric motor. During short trips the electric motor can power the vehicle, while during long drives the IC engine can power the vehicle. The vehicle can thus have engine only, motor only, or a combination of engine and motor mode of operation. The electric motor can also assist the engine during hill climbs and vehicle accelerations

\section{Dual mode HEV (Series-Parallel mode):}

Dual mode hybrid vehicles are parallel hybrids, but differ from them in the aspect, that an alternator (generator) is coupled to the IC engine that charges the battery. During normal operation, the IC engine turns both the drive train and the generator, which in turn feeds the battery pack through the electronic control unit.

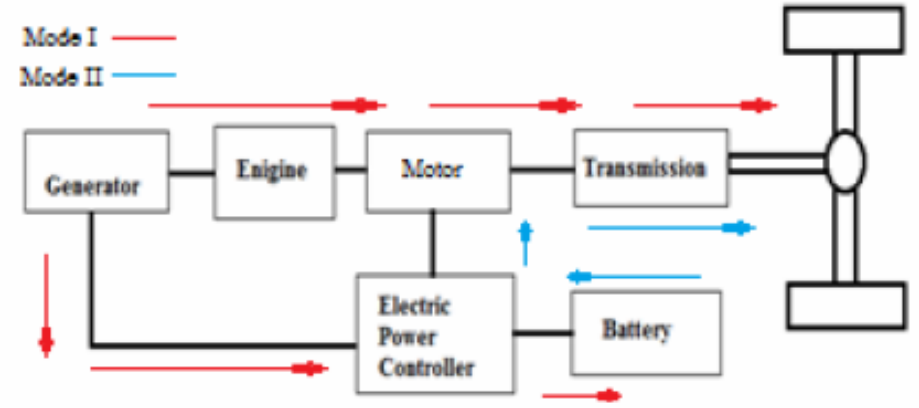

Figure 3 Dual Mode HEV 
During full-throttle acceleration, the electric motor gets power from the battery and assists the IC engine to attain the requested acceleration. Choosing a full size electric motor, which uses the IC engine only for charging the battery and occasionally for turning the wheels. This configuration exhibits dual capability and hence the name dual mode HEV configuration.

\section{Benefits of Electrical Transportation \\ - $\quad$ Reduced Pollution}

The transportation sector is now the largest source of carbon dioxide emissions in the U.S. The continued integration of EVs will help reduce this impact because they produce 54 percent less carbon dioxide emissions per mile than a conventional vehicle.

\section{- Cost Savings}

EV batteries convert 59 to 62 percent of energy into vehicle movement while gas powered vehicles use 17 and 21 percent. EV drivers spend about $\$ 1.2$ per gallon to charge, less than half the price of gasoline. The average operating cost of an EV is $\$ 485$ annually compared to $\$ 1,117$ for a conventional vehicle.

\section{- Economic Growth}

According to the U.S. Department of Energy, in 2019, the U.S. imported 19 percent of the petroleum it used. Using Electric Vehicles can reduce our energy dependency abroad and support the U.S. economy through the generation of new jobs, particularly in skilled electrical trades.

\section{LITERATURE REVIEW}

C. Chellaswamy, L. Balaji b, and T. Kaliraja (2020): This paper describes the hybrid renewable sources, for instance, the wind generator and the photovoltaic modules utilized to produce power to recharge the electric vehicles (EVs) storage system automatically. The current recharging mechanism of EVs requires recharging stations and it will affect the travelling distance for a long travel. This paper presents an automated charging mechanism (ACM) automatically recharges the battery packs, therefore, no need to wait for recharging EVs thereby increases the traveling distance. The proposed ACM is developed using MATLAB-Simulink model. The output voltage of the wind turbine is measured for three dissimilar speed scenarios. The performance of the solar photovoltaic had undergone different irradiance levels in the analysis. A series of studies have been carried out for the developed model of ACM under different load conditions. The total harmonic distortion (THD) of both the output current and voltage, efficiency, and the coverage distance of the vehicle has been studied. For illustrating the capability of ACM it is compared with commercial charging mechanism including different EV brands. The simulation result indicates that the performance of ACM is satisfactory for recharging the batteries of EVs without involving recharging stations. Automatic recharging of EV increases the usage of EVs thereby immensely reduce the fossil fuel vehicles as a result greatly reduced $\mathrm{CO} 2$ and COrelated emissions. Therefore the authors strongly believe that the method proposed decreases the complete travel time and as well as in increased EVs usage.

Camara, M. B., Gualous, H., Gustin, F., Berthon, A., \& Dakyo, B. (2019): This paper presents supercapacitor and battery modeling with an original energy management strategy in a hybrid storage technology. The studied dc power supply is composed of supercapacitorsand batteries. Supercapacitorare dimensioned for peak power requirement, and batteries provide the power in steady state. A bidirectional dc/dc converter is used between supercapacitors and the dc bus. Batteries are directly connected to the dc bus. The originality of this study is focused on supercapacitor behavior modeling and energy management strategy. The proposed strategy is based on a polynomial (RST) controller. For reasons of cost and existing components (not optimized) such as batteries and semiconductors, the experimental test benches are designed in reduced scale. The characterized packs of supercapacitor include two modules of ten cells in series for each one and present a maximum voltage of $27 \mathrm{~V}$. The proposed strategy is implemented on a PIC18F4431 microcontroller for two dc/dc converter topology controls. Experimental and simulation results obtained from the polynomial control strategy are presented, analyzed, and compared with that of classical proportional-integral control.An original strategy of the RST synthesis with polynomial coefficient estimation according to inductances, sampling period, and desired bandwidth has been presented in this paper. This polynomial control strategy is applied to two dc/dc converters for energy management between SCAP and battery. The resulting algorithms are robust and easy to do with a microcontroller or DSP devices.

\section{PROPOSED METHODOLOGY}

The different configurations of EV power supply show that at least one DC/DC converter is necessary to interface the FC, the Battery or the Supercapacitors module to the DC-link. In electric engineering, a DC to DC converter is a category of power converters and it is an electric circuit which converts a source of direct current (DC) from one voltage level to another, by storing the input energy temporarily and then releasing that energy to the output at a different voltage. The storage may be in either magnetic field storage components (inductors, transformers) or electric field storage components (capacitors). DC/DC converters can be designed to transfer power in only one direction, from the input to the output. However, almost all DC/DC converter topologies can be made bi-directional. A bi-directional converter can move power in either direction, which is useful in 
applications requiring regenerative braking. The amount of power flow between the input and the output can be controlled by adjusting the duty cycle (ratio of on/off time of the switch). Usually, this is done to control the output voltage, the input current, the output current, or to maintain a constant power. Transformerbased converters may provide isolation between the input and the output. The main drawbacks of switching converters include complexity, electronic noise and high cost.

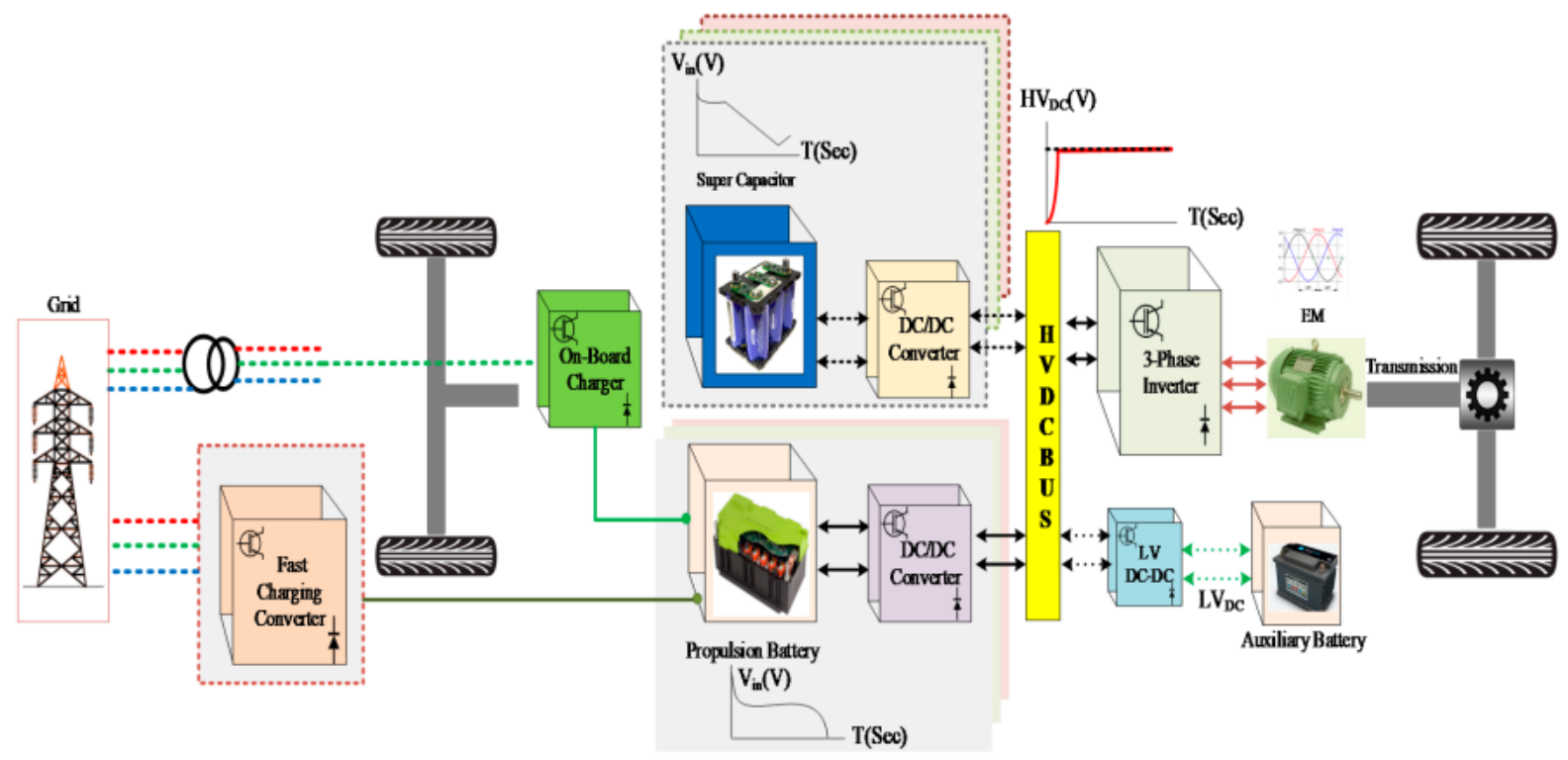

Figure 4Block diagram of an EV powertrain.

In the BEV and PHEV powertrains, electric sources (i.e., battery and/or supercapacitors) areconnected to the inverter through a high voltage (HV) DC bus to drive an HV three-phase electric motor (EM) as shown in Figure 4, which depicts a representative architecture of an EV powertrainwith charging systems.

A bidirectional DC/ DC converter, which interfaces an energy storage systems (such as batteries or supercapacitors (SCs)) to the DC-link, and the second, bidirectional DC/AC inverter, which is used to transfer the energy from the DC-link to the traction motor [such as three-phase permanent magnet synchronous motor (PMSM)]. The integration of a DC/DC converter with a DC/ AC inverter is an attractive option to form a $\mathrm{BEV}$ power train. Therefore, the right choice and integration of these converters play a key role in the successful development of efficient and high-performance BEV and PHEV systems.

Two-stage power conversion would make the converters bulky, expensive, and less efficient; hence, recent research has focused on single-stage power conversion. Some literature has proposed a single-stage power converter, which is able to provide the required output power by keeping the input sources in good health. Several choices for inverters are available for single-stage power conversions, such as voltage source inverter (VSI) and current source inverter (CSI), switched boost inverter (SBI), Z-source inverter (ZSI), and differential boost inverter (DBI). There are several limitations to VSI and CSI and, therefore, are not suitable for certain types of applications. For example, VSI cannot increase the AC output voltage level, and CSI cannot reduce the voltage level, and therefore for a wide range of voltage applications, it cannot operate independently. Moreover, they are non-interchangeable, and EMI noise affects both converters poorly. The switching devices and motor connected to the VSI or CSI face higherstresses, so the motor's constant power speed ratio is limited. Another type of inverter is switched boost inverter (SBI), which uses DC/DC boosted inversion system. Although it is not a pure single stage, it can act as a single-stage boost inverter. SBI consists of two parts: the boost part and the inverter part. The boosting part consists of an inductor and/ or switch and a diode which increases the DC voltage level, and then the full-bridge inverter that converts the DC voltage to AC. Since the inverter is based on high-speed switching, the output needs a filter to achieve sinusoidal pure AC voltage.

Different viable topologies of the DC-DC converter can be opted for BEV and PHEV powertrains. However, a small-sized, reliable, parameterized, lightweight, controllable, scalable, and efficient DC-DC converter has a higher demand in automotive industries. Some of these characteristics can be attained by using the interleaving technique of boost converter. Full-bridge boost converters can also be selected for BEVs and PHEVs if galvanic isolation is required between the source and the load. To overcome the hard switching characteristics of the DCDC converter, Zero-Voltage Switching (ZVS) and Zero-Current Switching (ZCS) source converters are employed in BEVs and PHEVs. 


\section{Battery Challenge}

The effectiveness of fuel consumption in today's hybrid vehicle depends on the efficiency of the batteries. Hybrid vehicle is designed to allow battery powered driving for short distance travel and traffic-jam condition. This short distance drive is also known as the all-electric range (AER). This kind of driving is usually observed when driving in the cities and resulted in a significant decrease of fuel consumption. Once the battery reaches depleting mode or low SOC threshold, combustion engine started and charged batteries. The depth discharge cycle of the HEV is suggested at above 50\% of SOC depth. Any value beyond this will reduce life cycle of the battery dramatically. This is demonstrated in Figure 5, where depth of discharge and number of life cycle of Ni$\mathrm{MH}$ and $\mathrm{Li}$-ion batteries are presented.

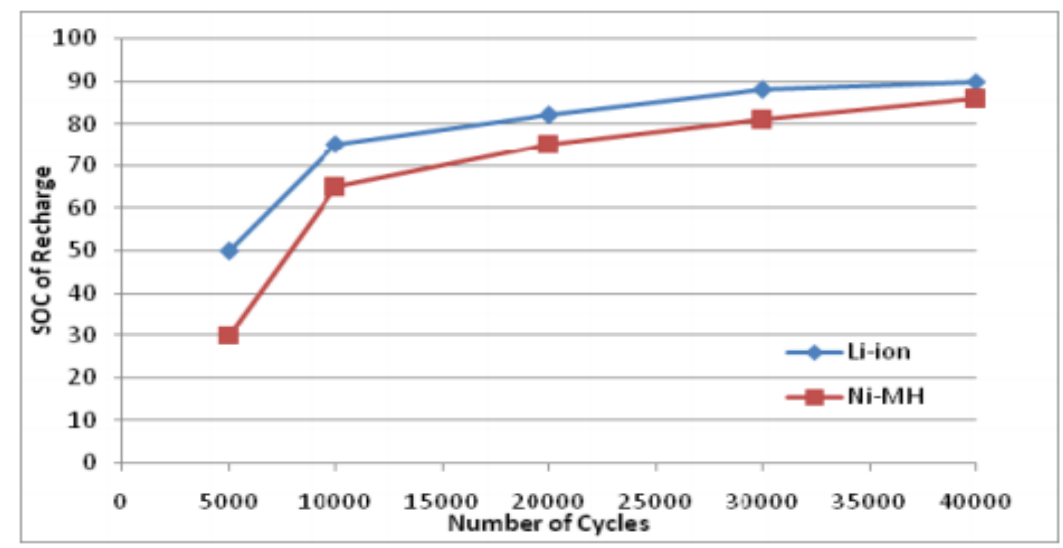

Figure5. The reduction of life cycle through state-of-charge of recharge

In order to increase AER and maximize storage capacity of the battery, its capability is measured in specific energy against weight $(\mathrm{Wh} / \mathrm{kg}$ ). Various battery types have different specific energy ranging from $20-40 \mathrm{Wh} / \mathrm{kg}$ for lead acid battery to $70-140 \mathrm{Wh} / \mathrm{kg}$ for Li-ion battery. This range is way too small when compared to about $12,000 \mathrm{Wh} / \mathrm{kg}$ of a gasoline. Nevertheless, the optimum battery capability for HEV lies in the range of 500 to $1000 \mathrm{Wh} / \mathrm{kg}$. If this is achieved, other technical challenges that still to be considered are cost, higher life cycle, short recharge time, performance, durability and overall weight and volume.

Judging from the overall characteristics of the different battery types, Li-Ion is the best candidate that can offer good performance, and high durability with less weight and volume. Nonetheless, price and long recharge time are still two factors to contemplate. In term of cost, $\mathrm{Li}$-ion price today is 35 Euro for $100 \mathrm{Wh}$ compared to 14 Euro of leadacid of the same capacity. The best margin price is $<5$ Euro for every $100 \mathrm{Wh}$. A light electric vehicle powered by $5 \mathrm{~kW}$ electric motor, with distance travelled of $240 \mathrm{~km}$ at constant speed of $80 \mathrm{~km} / \mathrm{h}$, will need energy storage capacity of about $15 \mathrm{kWh}$. This means that the cost of a battery electric vehicle (BEV) using Li-ion battery will achieve 5,250 Euro. Full recharge time will take about 5 hours to complete with the assumption that the energy capacity is $15 \mathrm{kWh}$ and recharge system is $3 \mathrm{~kW}$ per hour. This is impractical for long distance travelling. A workaround for this is to charge to only $50 \%$ capacity, which will take less than half an hour.

The relationship in the travelling time needed for various EVs like Chevy Volt, BMW Mini E, Ford Focus EV, Volvo Electric C30, Nissan LEAF and Tesla Roadster with the proposed system is shown in figure 4.3. Assuming all EVs are completely charged at the beginning and each EV shows the difference in capacity and the distance travelled. Here $10 \mathrm{~h}$ travelling time is taken and its respective distance is estimated inclusive of the waiting time to charge the vehicle.

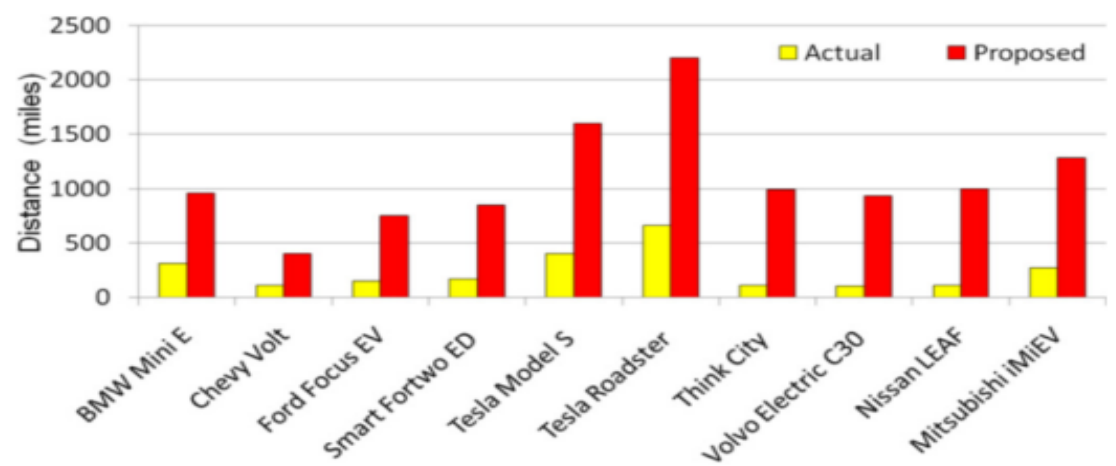

Figure 6. Comparison of travelling time of different EVs 
The proposed system compares the manufacturer's technical data of all EVs and the results are obtained. The obtained results depict a reduction in travelling time of 3:1 is achieved for the proposed system. Almost all electric vehicles produce zero direct emissions, which particularly helps to improve the air quality of cities. However, EVs produce fewer life cycle emission and most of the emissions are lower for electricity generation required to recharge the storage system. The comparison performed between total upstream emissions produced by different EV brands and the proposed automated charging mechanism is shown in Figure 7. It is observed that the BMW i3 produces less total upstream emission (175 g/ miles) and Toyota RAV4 produces largest total upstream emission ( $287 \mathrm{~g} / \mathrm{mile}$ ) compared to other EVs. The total upstream emission of proposed automated charging mechanism is estimated based on the life cycle and it produces minimum of $35 \mathrm{~g} / \mathrm{mile}$ and a maximum of $52.8 \mathrm{~g} / \mathrm{mile}$. The percentage of reduction varies from $77.4 \%$ to $80 \%$ and it shows that the proposed automated charging mechanism creates a green environment.

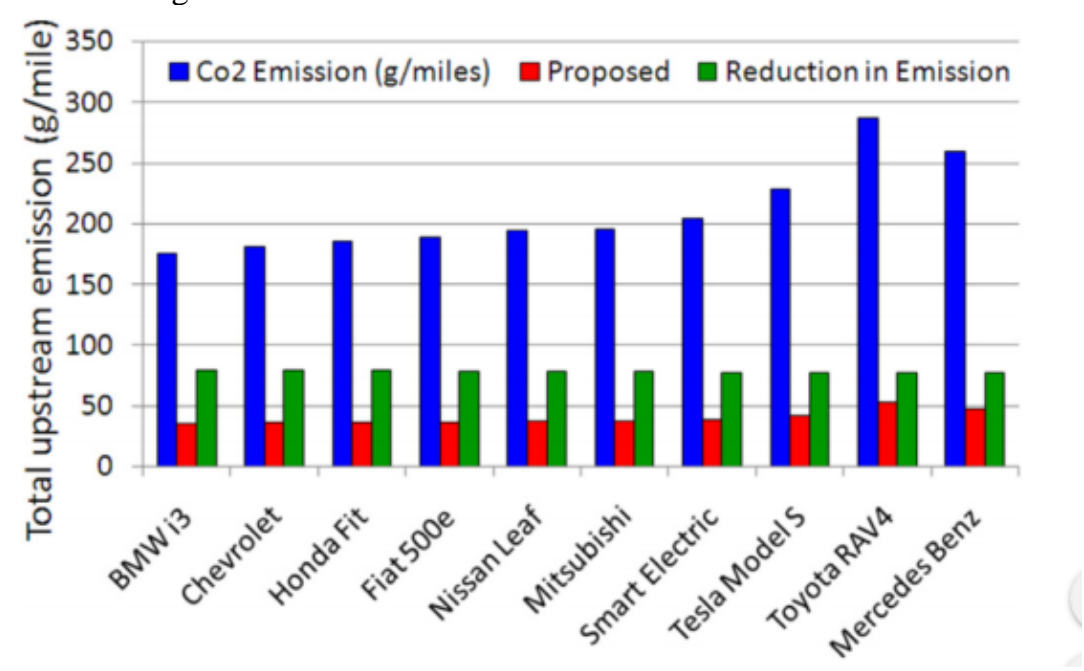

Figure 7. Comparison of total upstream emission between different EV brands

\section{CONCLUSION}

EVs represent one of the best promising technologies for green and sustainable transportation systems. The high penetration of EVs will have positive effects and benefits such as lesser fossil fuel reliance, significant reduction of GHG and toxic pollutant emissions, as well as the capability to contribute in the integration of renewable energy into existing electric grids. Thus the modelling of Electric Vehicle powertrain using hybrid convertor has designed. Moreover, the large variance in magnitude between the input and output imposes severe stresses on the switch and this topology suffers from high current and voltage ripples and also big volume and weight. The battery challenges in electrical vehicle has also discussed in this paper. For long distance travel, few countries are utilizing recharging stations and the travelling distance depends on the vehicle's energy storage capacity. From the power produced by the hybrid renewable charging mechanism, we state that this system can be used in EVs with a special type of wind generator which capable to utilize high-speed wind.. It is expected that this review can help researchers and engineers better understand the state-of the-art and contribute more to this field.

\section{REFERENCES}

1. Chellaswamy, C., Balaji, L., \& Kaliraja, T. (2020). Renewable energy based automatic recharging mechanism for full electric vehicle. Engineering Science and Technology, an International Journal. doi:10.1016/j.jestch.2019.07.007

2. Camara, M. B., Gualous, H., Gustin, F., Berthon, A., \& Dakyo, B. (2019). DC/DC Converter Design for Supercapacitor and Battery Power Management in Hybrid Vehicle Applications-Polynomial Control Strategy. IEEE Transactions on Industrial Electronics, 57(2), 587-597. doi:10.1109/tie.2009.2025283

3. Shen W, Cui X. Impact of electric vehicles and renewable energy systems on cost and emission of electricity. In: Proceedings of the 7th IEEE conference on industrial electronics and applications (ICIEA); 2012. p. 120-5

4. Dreher, J.R.; Marangoni, F.; Ortiz, J.L.; Martins, M.D.; Câmara, H.T. Integrated DC/DC converters for high step-up voltage gain applications. In Proceedings of the 2018 18th International Power Electronics and Motion Control Conference (EPE/PEMC), Novi Sad, Serbia, 4-6 September 2018.

5. Channegowda, J.; Pathipati, V.K.; Williamson, S.S. Comprehensive review and comparison of DC fast charging converter topologies: Improving electric vehicle plug-to-wheels efficiency. In Proceedings of the 2019 IEEE 24th International Symposium on Industrial Electronics (ISIE), Buzios, Brazil, 3-5 June 2019; pp. 263-268. 
6. Gavagsaz-Ghoachani, R.; Zandi, M.; Martin, J.P.; Pierfederici, S.; Phattanasak, M.; Nahid-Mobarakeh, B. Control of a Two-Phase Interleaved Boost Converter with Input LC Filter for Fuel Cell Vehicle Applications. In Proceedings of the 2017 IEEE Vehicle Power and Propulsion Conference (VPPC), Belfort, France, 11-14 December 2017; pp. 1-5

7. Hannan M.A., Azidin F.A., Mohamed A., Light Vehicle Energy Management System using Multi-Power Sources, Przeglad Elektrotechniczny (Electrical Review), 3b (2020), 197-204.

8. Chan, C.C., Bouscayrol, A., Chen, K. Electric, Hybrid, and Fuel-Cell Vehicles: Architectures and Modeling, IEEE Trans. Vehicular Technology, 59 (2018), Nr. 2, 589-597

9. Lachichi, A., Schofield, N. (2006). Comparison of DC-DC Converter Interfaces for Fuel Cells in Electric Vehicle Applications, Proceedings of VPPC'06 IEEE Conference on Vehicle Power \& Propulsion, pp. 1 6, ISBN 1-4244-0158-5, Windsor, UK, September 6-8, 2018

10. M. Elsied, A. Oukaour, H. Gualous, R. hassan, A. amin, “An advanced dc/dc boost converter for hybrid electric vehicles applications based on Proton Exchange Membrane Fuel Cell (PEMFC) ", the 6th International Conference of fundamentals and development of fuel cells', France, Toulouse, 3-5 Feb2018 